\title{
ACIDENTES DO TRABALHO RURAL NO INTERIOR PAULISTA
}

\author{
Monica La Porte Teixeira \\ Rosa Maria Vieira de Freitas
}

\begin{abstract}
Resumo: No interior paulista, coabitam alta tecnologia e acidentes do trabalho estritamente manuais, ou seja, o alto índice de tecnologia utilizada na agropecuária não descartou a possibilidade de existirem acidentes com trabalhadores rurais, que exercem atividades com baixo padrão tecnológico, sobretudo as vinculadas ao plantio e corte de cana-de-açúcar. Onde eles, em sua maioria, sofrem acidentes no exercício diário de sua profissão. Palavras-chave: trabalhador rural; acidente do trabalho; atividade agrícola.
\end{abstract}

\begin{abstract}
In the interior of São Paulo State, highly developed farming technologies coexist with accidents that occur during the execution of strictly manual tasks. From this, one can conclude that advanced farming technologies have not eliminated accidents among rural laborers who carry out low-technology tasks, especially those tasks related to the planting and harvesting of sugar cane. It is in this area that most laborers suffer accidents in their day-to-day work.

Key words: rural laborers; work-related accident; agricultural activity.
\end{abstract}

1 intenção deste artigo é expor, de forma sucinta, os principais resultados da pesquisa sobre acidentes do trabalho rural realizada pela Fundação Seade/Fundacentro e despertar um pouco a atenção para as diversidades existentes no interior paulista, como a riqueza agrária e os diferentes problemas enfrentados pelos trabalhadores rurais no exercício de suas atividades profissionais.

Mais que oportuno, o debate sobre a temática do acidente do trabalho no meio rural é imprescindível nos tempos modernos, pois este é um espaço onde se sucederam grandes transformações tecnológicas que modificaram a vida dos trabalhadores desse setor, em especial para o Estado de São Paulo, importante palco dessas transformações.

Contudo, são precários os estudos e a disponibilidade de dados sobre o tema. Os existentes, tais como, os trabalhos de Lopes (1982:12-17) e de Alessi e Navarro (1997:111-121) entre outros, importantes e fundamentais, são específicos a determinadas áreas ou a estudos de casos. Para uma área tão extensa como o Estado de São Paulo e com informações minuciosas referentes aos trabalhadores que se apresentam mais suscetíveis aos acidentes, es- tes estudos eram praticamente inexistentes até a realização da pesquisa Seade/Fundacentro, que ocorreu em todas as agências da Previdência Social, mediante a coleta das Comunicações de Acidentes do Trabalho - CAT, instrumento no qual os trabalhadores registrados no INSS têm seu acidente cadastrado com informações valiosissímas.

Uma das características positivas dessa pesquisa realizada no meio rural foi o grande volume de eventos coletados, o que demonstra que muitos dos acidentes que envolveram trabalhadores rurais foram notificados, ao contrário do que se supunha (Fundação Seade/Fundacentro, 2001). Do total dos acidentes ocorridos no Estado de São Paulo entre 1997 e 1999, registrados na Previdência Social, 10,4\% eram de acidentes rurais coletados pela pesquisa.

\section{SÃO PAULO - UMA POTÊNCIA DO SETOR PRIMÁRIO}

O Estado de São Paulo sobressai-se não só por ser o Estado mais populoso e industrializado do Brasil, mas também por possuir um saliente centro agropecuário, destacando-se em relação ao conjunto nacional. 
Concentra excelentes condições em virtude da boa qualidade do solo e do clima, além de possuir excelentes fatores estruturais, técnicas aplicadas que favorecem o plantio de culturas diversificadas, como algodão herbáceo, amendoim, cana-de-açúcar, laranja, tomate, arroz, banana, feijão, mandioca, milho, soja, trigo, batata-inglesa, uva e café. Embora tenha perdido o título de centro de cafeicultura para o Paraná, ainda se destaca como um dos grandes produtores dessa cultura agrícola, entre outros. Outro atrativo que facilitou o desenvolvimento agrícola do Estado é a disponibilidade de um bom aparelhamento do porto de exportação, o porto de Santos.

Um dos produtos agrícolas de maior relevância é a canade-açúcar com incremento apreciável. Sua área colhida corresponde a cerca de $51 \%$ da produção brasileira (Censo Agropecuário de 1995/96), o que garante o suprimento da indústria açucareira, que se firmou como uma das mais importantes do país. De acordo com dados da Pesquisa de Atividade Econômica Paulista - Paep 96 realizada pela Fundação Seade, a produção de cana-de-açúcar sobres- sai-se na atividade agroindustrial ${ }^{1}$ em São Paulo, como a primeira nesse ramo de atividade, no que se refere aos indicadores emprego, receita, remuneração e valor adicionado (Belik et al., 1999).

A pecuária é outra atividade do setor primário que concorre sensivelmente para o processo produtivo da economia regional, principalmente nas áreas vinculadas à bovinocultura de corte e de leite; à avicultura, que se firmou como importante complexo integrado de granjas e abatedores; e à suinocultura, esta última como produtora de matrizes e reprodutores. Essas atividades apresentam no Estado de São Paulo, concomitantemente, modernas e grandes instalações de abate, como também pequenos abatedores tradicionais. Quanto ao pessoal empregado, a participação da pecuária é pequena comparada à atividade agrícola (Silva; Balsadi; Grossi, 1997). Em relação ao volume dos efetivos de rebanho, a maior concentração de cabeças de boi situa-se mais a oeste, nas mesorregiões de São José do Rio Preto, Presidente Prudente e Araçatuba, enquanto os efetivos de aves localizam-se mais a noroes-

MAPA 1

Produtos de Lavoura Temporária e Permanente, por Área Colhida (Hectare), segundo Mesorregiões Geográficas Estado de São Paulo -1995/1996

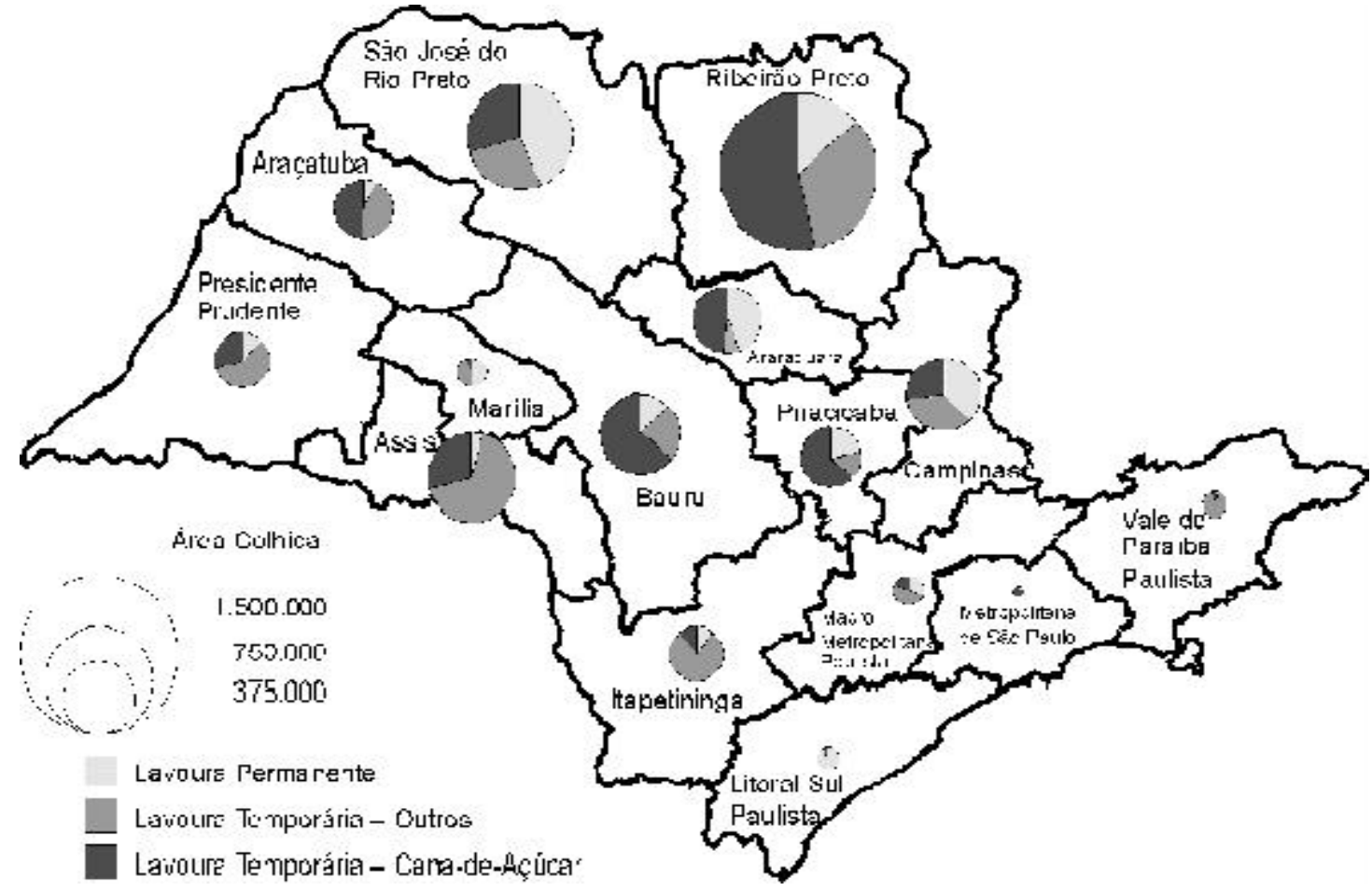

Fonte: Fundação IBGE. Censo Agropecuário de 1995/1996. 
te e nordeste, nas mesorregiões de Campinas, Piracicaba e Araraquara, e a criação de suínos mescla-se, destacando-se as mesorregiões de Campinas, São José do Rio Preto e Bauru (Censo Agropecuário de 1995/1996).

Quanto à piscicultura, o litoral de $622 \mathrm{~km}$, tem numerosas colônias de pescadores, mas é especialmente nas proximidades de Santos e Cananéia que se concentram atividades pesqueiras organizadas. Segundo Silva, Balsadi e Grossi (1997), o aumento dessa atividade, no Estado de São Paulo, deve-se ao vertiginoso crescimento dos pesquepagues, e a demanda para o processamento industrial.

O Mapa 1 apresenta as principais áreas de colheita de lavoura permanente e temporária do Estado, onde a cultura de cana-de-açúcar, em razão do grande valor na produção agrícola, encontra-se separada. ${ }^{2}$

Observa-se por área colhida, grande diversidade de produtos agrícolas no espaço territorial paulista, onde o destaque cabe para as lavouras temporárias, principalmente para a cultura de cana-de-açúcar, que, com pouquíssimas exceções, espalha-se por todo o interior do Estado. As mesorregiões que mais se sobressaem nesse cultivo são as de Ribeirão Preto, Piracicaba, Araraquara e Bauru, com exceção dessa última, são regiões do Estado onde se concentram a agricultura de maior valor comercial, em particular as atividades dos complexos agroindustriais de canade-açúcar e da laranja (Balsadi et al., 2001).

As diversidades no setor agrícola paulista não só se restringem aos tipos de culturas existentes, mas também às distintas técnicas e divisões trabalhistas, tanto nas atividades de plantio e corte, como nas atividades da agroindústria.

Com relação à demanda de mão-de-obra, a cana-deaçúcar, mais uma vez, aparece como principal cultura a utilizar mão-de-obra agrícola no Estado de São Paulo (Belik et al., 1999), onde muitos desses trabalhadores exercem atividades com baixo padrão tecnológico. Regionalmente, conforme dados da Paep, a área do Estado que teve o maior peso relativo à demanda de mão-de-obra, durante os anos 90, foram as mesorregiões situadas mais a noroeste do Estado, depois as situadas a nordeste, centro-oeste e centro-sul (Balsadi et al., 2001).

O progresso do setor agrícola paulista intensificou-se a partir dos anos 50. Foi com o crescimento urbano e econômico do Estado que se desencadeou o processo de modernização tecnológica na agricultura, acarretando modificações nas práticas agrícolas, como o aumento do trabalho mecânico e a ampliação do uso de insumos químicos, mudanças que garantiram o aumento da produtivi- dade com menor utilização da mão-de-obra. Contudo, algumas práticas agrícolas continuam a ser trabalhadas de forma manual, como há 100 anos. Diante desse panorama, conclui-se que o perfil do trabalhador rural paulista é diversificado, pois convive no mesmo espaço com a alta tecnologia e o trabalho manual.

\section{PROBLEMÁTICA DO ACIDENTE DO TRABALHO}

Todo o trabalhador no exercício de sua profissão está sujeito a um acidente do trabalho, e algumas profissões apresentam probabilidades maiores que outras. A teoria do risco de acidente do trabalho aponta os principais agentes de risco ocupacionais presentes no ambiente de trabalho, são eles: físicos, mecânicos, biológicos, ergonômicos (considerados a partir da Segunda Guerra Mundial, seriam as condições de adequação dos instrumentos de trabalho ao homem) e mais recentemente, os riscos psicossociais, em razão da crescente exposição do trabalhador a situações de tensão e estresse no trabalho.

A definição de acidente do trabalho no Brasil existe desde 1919 como conceito jurídico. No entanto, somente nos últimos anos é que se ampliou seu espaço, preocupando a classe médica e dando origem à medicina do trabalho. Essa inquietação cresceu de um jeito que expandiu o âmbito industrial, surgindo vários trabalhos referentes ao acidente do trabalho propriamente dito, à higiene industrial e à segurança do trabalho, entre outros (Ribeiro, 2000).

A Lei no 8.213, que rege desde 1991 o acidente do trabalho no Brasil, considera em seu artigo 19: "acidente do trabalho é todo aquele que ocorre pelo exercício do trabalho, a serviço da empresa, provocando lesão corporal ou perturbação funcional que cause a morte ou a redução, permanente ou temporária, da capacidade para o trabalho". Ademais, nos artigos 20 e 21 "Consideram-se ainda como acidentes do trabalho, outras entidades mórbidas, tais como as doenças profissionais; os acidentes ligados ao trabalho, embora o trabalho não seja a única causa que haja contribuído para a morte ou lesão do segurado: os acidentes ocorridos no local de trabalho decorrentes de atos intencionais ou não de terceiros ou companheiros de trabalho; os desabamentos; as inundações; os incêndios e outros casos fortuitos ou decorrentes de força maior; as doenças provenientes de contaminação acidental no exercício da atividade; os acidentes, ainda que ocorridos fora do horário ou local de trabalho, na execução de ordem da 
empresa, mesmo para estudos ou realização de serviços externos; no percurso da residência para o local de trabalho, ou deste para aquele". Assim, para efeito da Previdência Social, os acidentes do trabalho são classificados em três categorias:

- Acidentes-Tipo: são os acidentes decorrentes da atividade profissional desempenhada pelo trabalhador;

- Acidentes de Trajeto: são os acidentes ocorridos no trajeto entre a residência e o local de trabalho e nos horários de refeição;

- Doenças do Trabalho: são os acidentes ocasionados por qualquer tipo de doença peculiar a determinado ramo de atividade (Waldvogel, 1999).

Alterações expressivas com relação ao trabalho agrícola também foram observadas na Lei Acidentária. Até 1991, a classe trabalhista rural sofria uma distinção na forma de pagamento dos benefícios relacionados ao acidente do trabalho, que a deixavam, mais uma vez, em desvantagem em relação ao trabalhador urbano. Com a Lei Acidentária de 1991 ocorreram duas importantes alterações. A primeira considera que, para efeito de pagamento de benefícios decorrentes de acidentes do trabalho, o trabalhador rural tem os mesmos direitos do trabalhador urbano, equiparando-o, com relação ao pagamento dos benefícios, ao trabalhador urbano (Waldvogel, 1999).

A segunda refere-se à notificação dos acidentes do trabalho ao Instituto Nacional de Seguridade Social - INSS, que deixa de ser prerrogativa das empresas, e pode ser efetuada pelos sindicatos dos trabalhadores, pelo Sistema Único de Saúde - SUS e pelos próprios trabalhadores ou seus familiares (Waldvogel, 1999).

A Organização Internacional do Trabalho - OIT afirma que o trabalho rural é significativamente mais perigoso que outras atividades e estima que milhões de agricultores sofram sérios problemas de saúde. ${ }^{3}$

São distintos e reais os percalços do trabalhador rural paulista. Convivem tanto com a mais alta tecnologia agrária como com condições mais simples de plantio, corte, etc. Mesmo com o alto desenvolvimento tecnológico no setor primário, no qual o Estado de São Paulo destaca-se em relação ao resto do país, apresenta trabalhadores rurais em atividades puramente braçais e de risco de vida, como os cortadores de cana. Considerando-se que em São Paulo cerca de $75 \%$ da área plantada da cana-de-açúcar ${ }^{4}$ ainda é cortada manualmente após o processo de queimada, como há 100 anos (Revista Ecologia e Desenvolvimento, 2000:42-43), dessa forma, conjectura-se que o número de acidentes do trabalho que envolve esses trabalhadores é enorme, em razão das queimadas, ${ }^{5}$ da postura física exigida para o corte da cana e da simples utilização de suas ferramentas básicas de trabalho, como o afiado facão, que sem o material de proteção torna-se um perigo em potencial nas mãos habilidosas e apressadas do trabalhador.

O desenvolvimento tecnológico do campo resultou não só na utilização de novas técnicas agrícolas, mas também em novos tipos de acidentes do trabalho. Com a intenção de aumentar a produtividade com menor utilização de mãode-obra, ampliou-se a força mecânica (máquinas) e a utilização de defensivos agrícolas, situação a qual diversos trabalhadores rurais não estavam preparados para utilizá-las de forma adequada, o que desencadeou sérios acidentes.

No entanto, os trabalhadores rurais não estão sujeitos somente a acidentes-tipo, os acidentes ocorridos no trajeto, entre a residência e o local de trabalho e vice-versa, tornaram-se mais próximos dessa classe trabalhista. A valorização das terras, ocorrida cada vez mais com a utilização tecnológica, teve como uma das conseqüências a expulsão do trabalhador rural da terra, obrigando-o a migrar para as cidades, levou-o a realizar todos os dias o deslocamento entre grandes áreas, muitas vezes, em péssimas condições, determinadas pela qualidade das estradas e do tipo de transporte utilizado (Waldvogel, 1999).

Como a identificação e a dimensão a priore de uma situação pode contribuir para a prevenção de um problema ou diminuir sua extensão, tomar conhecimento da questão acidentária relativa aos trabalhadores rurais, identificando-os e dimensionando seus principais problemas de saúde e de segurança, poderá enriquecer o debate dessa temática, como também colaborar para orientar políticas de prevenção de acidentes e doenças do trabalho em área rural. Assim, foi com esse intuito, que se realizou numa "parceria" entre a Fundação Seade e a Fundacentro, uma pesquisa nas agências e postos do INSS do Estado de São Paulo, com a finalidade de levantar os casos de acidentes do trabalho ocorridos no meio rural.

\section{LEVANTAMENTO DOS CASOS DE ACIDENTES DO TRABALHO OCORRIDOS NO MEIO RURAL}

\section{Metodologia de Coleta dos Dados}

A pesquisa realizada pela Fundação Seade/Fundacentro, em todas as 115 agências do INSS do interior paulista, levantou 58.204 acidentes do trabalho, ocorridos em área rural no período entre 1997 e 1999. 
Essa pesquisa foi pioneira, uma vez que sua abrangência geográfica cobriu todo o Estado de São Paulo e contemplou todas as atividades desenvolvidas nas áreas rurais. O levantamento realizado representa $10,4 \%$ de todos os acidentes registrados na Previdência Social no período estudado.

Constituiu-se de coleta manual nos arquivos do INSS, por meio do rastreamento de todos os processos existentes, identificando e selecionando os acidentes do trabalho registrados na Comunicação de Acidente do Trabalho CAT.

A seleção dos processos de acidentes do trabalho seguiu os seguintes critérios:

- acidente descrito no processo de acidente do trabalho ocorreu em área rural;

- o acidente descrito no processo de acidente do trabalho correspondeu a uma atividade tipicamente rural (Relatório Seade/Fundacentro, 2001).

Foi elaborado um formulário específico para a coleta, com levantamento de diversas características referentes ao acidentado, ao empregador e ao acidente. Logo após, os dados passaram por processo de crítica e revisão, e, em seguida, realizadas a codificação e a digitação. Os dados, após digitados e consistidos, foram organizados em farto material de banco de dados, com diversas informações referentes aos acidentes-tipo, de trajeto e doenças do trabalho ocorridos em áreas rurais do Estado de São Paulo.

\section{Principais Resultados}

Abrangendo somente os trabalhadores registrados na Previdência Social, a pesquisa levantou 58.204 acidentes do trabalho em áreas rurais. Desses acidentes, 929 eram de trajeto, 5.354 doenças do trabalho e 51.644 aciden- tes-tipo. Apenas 277 acidentes não puderam ser classificados.

Ocorreram em média 53,2 acidentes do trabalho por dia envolvendo trabalhadores da área rural paulista, o que se classifica como uma alta proporção diária de acidentes entre 1997 e 1999. Vale ressaltar que os acidentes de trajeto apresentaram a menor média, menos de 1 acidente por dia no decorrer do período. O grande causador dessa média elevada são os acidentes-tipo, com 47,2 acidentes por dia, ou seja, foi no desempenho de sua atividade profissional que o trabalhador rural apresentou a maior possibilidade diária de acidentes do trabalho. Como conseqüência desses acidentes, observa-se que a maioria resultou em incapacidade temporária, enquanto a incapacidade permanente e o óbito atingiram uma parcela bastante reduzida de trabalhadores.

Com praticamente $89 \%$ os acidentes-tipo, em sua maioria teve como conseqüência a incapacidade temporária. Foram os acidentes de trajeto que apresentaram a menor participação no total dos acidentes, entretanto, proporcionalmente, são eles que resultam mais em óbitos, por serem, mais violentos.

As doenças do trabalho, que perfizeram $10 \%$ dos acidentes nesse período, resultaram, praticamente em sua totalidade, em incapacidade temporária, não apresentando nenhum óbito. Entre os tipos mais presentes das doenças do trabalho encontram-se os traumatismos, o mal súbito, o estresse e as lesões por esforços repetitivos. É pertinente observar que é muito mais difícil estabelecer nexo causal entre a lesão adquirida e a atividade profissional desempenhada pelo trabalhador para doença profissional que para o acidente do trabalho tipo ou de trajeto.

Segundo a Classificação Nacional de Atividade Econômica - CNAE, para os acidentes-tipo, 70,5\% dos acidentes estão associados a empresas relacionadas à agricultura, pecuária, silvicultura e exploração florestal, e são

TABELA 1

Distribuição dos Acidentes do Trabalho em Áreas Rurais, por Motivo, segundo Conseqüência Estado de São Paulo-1997/1999

\begin{tabular}{|c|c|c|c|c|c|c|c|c|}
\hline \multirow{2}{*}{ Conseqüência } & \multicolumn{2}{|c|}{ Total (1) } & \multicolumn{2}{|c|}{ Acidentes-Tipo } & \multicolumn{2}{|c|}{ Doenças do Trabalho } & \multicolumn{2}{|c|}{ Acidentes de Trajeto } \\
\hline & Casos & $\%$ & Casos & $\%$ & Casos & $\%$ & Casos & $\%$ \\
\hline Total & 58.204 & 100,00 & 51.644 & 88,73 & 5.354 & 9,20 & 929 & 1,60 \\
\hline Incapacidade Temporária & 58.049 & 99,73 & 51.508 & 99,74 & 5.353 & 99,98 & 918 & 98,82 \\
\hline Óbito & 90 & 0,15 & 76 & 0,15 & 0 & 0 & 10 & 1,08 \\
\hline Invalidez Permanente & 65 & 0,11 & 60 & 0,12 & 1 & 0,02 & 1 & 0,11 \\
\hline
\end{tabular}

Fonte: Fundação Seade; Fundacentro/MTE.

(1) Inclui 277 casos ignorados. 
destaque deste grande grupo, as atividades que envolvem o cultivo de cana-de-açúcar $(40,3 \%)$ e a produção mista, ou seja, lavoura e pecuária $(39,2 \%)$. Das atividades relacionadas, só na pecuária e na criação de animais observaram-se, proporcionalmente, poucos acidentes.

Outros grandes grupos de destaque são: o de fabricação de produtos alimentícios e bebidas, onde as usinas de açúcar perfazem $61,4 \%$ dos acidentes-tipo e $13,1 \%$ são de acidentes relacionados à fabricação de aguardentes e bebidas destiladas; e o de produção de álcool. Todos os grandes grupos da CNAE, que apresentaram participação considerável de acidentes do trabalho estão de alguma forma vinculados à cana-de-açúcar.

Ainda segundo a CNAE, para a doença do trabalho observa-se novamente que o grupo de trabalhadores inseridos em empresas com atividades econômicas relacionadas a agricultura, pecuária, silvicultura e exploração florestal destaca- se dos demais, com quase $75 \%$ do total das doenças do trabalho. Repetindo, dentro desse grupo, nas atividades mencionadas, sobressaem-se mais os trabalhadores relacionados ao cultivo da cana-de-açúcar com $52,1 \%$ e os da produção mista, lavoura e pecuária com $37,4 \%$.

Verifica-se, para as doenças do trabalho, semelhante participação relativa para os outros dois grandes grupos da CNAE, já mencionadas nosacidentes-tipo, ou seja, fabricação de produtos alimentícios e bebidas e a produção de álcool. Onde ambos apresentaram uma supremacia de atividades relacionadas, mais uma vez, ao cultivo e à produção da cana-de-açúcar.

Ao lançar um olhar no agente causador, nota-se que cerca de 49,9\% dos acidentes-tipo foram causados por ferramentas de trabalho, entre elas pode-se citar o facão e o podão, ferramentas utilizadas sobretudo pelos cortadores de cana-de-açúcar, com força e de forma precisa. Essa in-

TABELA 2

Distribuição dos Acidentes do Trabalho em Área Rural, segundo Principais Grupos da Classificação Nacional de Atividade Econômica e Subgrupos Estado de São Paulo-1997/1999

\begin{tabular}{|c|c|c|c|c|}
\hline \multirow{2}{*}{ Classificação Nacional de Atividade Econômica } & \multicolumn{2}{|c|}{ Acidentes-Tipo } & \multicolumn{2}{|c|}{ Doenças do Trabalho } \\
\hline & Total & $\%$ & Total & $\%$ \\
\hline TOTAL & 51.644 & 100,00 & 5.354 & 100,00 \\
\hline Agricultura, Pecuária e Serviços Relacionados com essas Atividades & 36.388 & 70,46 & 3.970 & 74,15 \\
\hline Cultivo de cana-de-açúcar & 14.661 & 40,29 & 2.069 & 52,12 \\
\hline Produção mista: lavoura e pecuária & 14.275 & 39,23 & 1.483 & 37,36 \\
\hline Atividades de serviços relacionados com a agricultura & 4.752 & 13,06 & 279 & 7,03 \\
\hline Cultivo de frutas cítricas & 993 & 2,73 & 53 & 1,34 \\
\hline Criação de aves & 462 & 1,27 & 28 & 0,71 \\
\hline Criação de bovinos & 393 & 1,08 & 7 & 0,18 \\
\hline Cultivo de café & 216 & 0,59 & 11 & 0,28 \\
\hline Atividades de serviços relacionados com a pecuária, exceto atividades veterinárias & 212 & 0,58 & 13 & 0,33 \\
\hline Cultivo de cereais & 103 & 0,28 & 7 & 0,18 \\
\hline Cultivo de flores e plantas ornamentais & 95 & 0,26 & 17 & 0,43 \\
\hline Outros & 226 & 0,62 & 3 & 0,08 \\
\hline Fabricação de Produtos Alimentícios e Bebidas & 1.527 & 2,96 & 144 & 2,69 \\
\hline Usinas de açúcar & 937 & 61,36 & 107 & 74,31 \\
\hline Fabricação, retificação, homogeneização e mistura de aguardentes e outras bebidas destiladas & 200 & 13,10 & 7 & 4,86 \\
\hline Abate de aves e outros pequenos animais e preparação de produtos de carne & 108 & 7,07 & 12 & 8,33 \\
\hline Abate de reses, preparação de produtos de carne & 105 & 6,88 & 5 & 3,47 \\
\hline Refino e moagem de açúcar & 62 & 4,06 & - & 0,00 \\
\hline Produção de sucos de frutas e de legumes & 61 & 3,99 & 6 & 4,17 \\
\hline Outros & 54 & 3,54 & 7 & 4,86 \\
\hline Produção de Álcool & 1.119 & 2,17 & 210 & 3,92 \\
\hline Produção de álcool & 1.118 & 99,91 & 210 & 100,00 \\
\hline Refino de petróleo & 1 & 0,09 & - & 0,00 \\
\hline Outros & 8.649 & 16,75 & 623 & 11,64 \\
\hline Ignorado & 3.961 & 7,67 & 407 & 7,60 \\
\hline
\end{tabular}

Fonte: Fundação Seade; Fundacentro/MTE. 
formação vem de encontro ao observado nos dados do tipo de acidente, no qual destacam-se os acidentes com objetos cortantes/contundentes $(44,3 \%)$ e os traumatismos ou lesões causados por instrumentos de trabalho $(11,7 \%)$.

Outro agente causador relevante nosacidentes-tipo foi o contato com animais e plantas venenosas com 14,7\% dos casos, situação decorrente do meio ambiente do trabalhador do campo, explicando o quarto principal tipo de acidente, que são os acidentes causados por plantas (Tabelas 3 e 4).

A mesma análise feita para as doenças do trabalho mostra que os acidentes que envolvem torção, mal jeito são maioria absoluta, com 94,5\% dos eventos. Nesse caso, os principais problemas são os terrenos irregulares, buracos, saltos do caminhão, posições inadequadas, movimentos bruscos, etc., e nos demais agentes causadores nenhum deles apresentou volume de eventos considerável para análise quando observados isoladamente.

Com relação a variável tipo de acidente, destacam-se para as doenças do trabalho, com um pouco mais da metade das doenças registradas $(51,3 \%)$ - os traumatismos ou as lesões decorrentes de movimentos. Importantes e destacadas apareceram, com 47,1\%, lesões por esforços repetitivos/mal súbito/estresse. Esses tipos de doenças do trabalho aparecem cada vez mais com freqüência no cotidiano de todo o trabalhador, ou seja, estão cada vez mais evidentes e passíveis de reconhecimento.

Do total dos acidentes do trabalho sofridos pelos trabalhadores da área rural, 6,5\% não afastaram o trabalhador de suas atividades profissionais, 61,2\% o afastaram

TABELA 3

Distribuição dos Acidentes do Trabalho em Áreas Rurais, segundo Principais Agentes Causadores Estado de São Paulo - 1997/1999

\begin{tabular}{|c|c|c|c|c|}
\hline \multirow{2}{*}{$\begin{array}{l}\text { Principais Agentes } \\
\text { Causadores }\end{array}$} & \multicolumn{2}{|c|}{ Acidentes-Tipo } & \multicolumn{2}{|c|}{ Doenças do Trabalho } \\
\hline & Total & $\%$ & Total & $\%$ \\
\hline Total & 51.644 & 100,00 & 5.354 & 100,00 \\
\hline Ferramentas de trabalho & 25.770 & 49,90 & 49 & 0,92 \\
\hline \multicolumn{5}{|c|}{ Contato com animais e plantas } \\
\hline venenosas & 7.610 & 14,74 & 15 & 0,28 \\
\hline Outros & 5.290 & 10,24 & 106 & 1,98 \\
\hline Queda & 3.116 & 6,03 & - & - \\
\hline Torção, maljeito & 2.756 & 5,34 & 5.060 & 94,51 \\
\hline Objetosinanimados & 2.544 & 4,93 & 16 & 0,30 \\
\hline \multicolumn{5}{|l|}{ Escorregar, desequilibrar, } \\
\hline Tropeçar, pisar em falso & 2.484 & 4,81 & - & - \\
\hline Seminformação & 2.048 & 3,97 & 107 & 2,00 \\
\hline Ignorado & 26 & 0,05 & 1 & 0,02 \\
\hline
\end{tabular}

Fonte: Fundação Seade; Fundacentro/MTE. até 15 dias, 32,3\% resultaram em período de afastamento superior a 15 dias.

De acordo com a classificação do acidente, nota-se que as doenças do trabalho apresentaram proporção um pouco maior de casos que não resultaram em afastamento em relação aos acidentes-tipo e ao total dos acidentes coletados. Foi a doença do trabalho que também registrou a mais significativa proporção de trabalhadores com afastamento entre 15 dias e 1 mês. Percebe-se que, após três meses de afastamento, a proporção de trabalhadores afastados por algum tipo de acidente diminui bastante, alcançando menos de $1 \%$ do total dos acidentes, independente de sua classificaçãotipo, trajeto ou doenças do trabalho.

O afastamento do trabalhador de suas atividades laborais acima de 15 dias pode trazer prejuízos dos pontos de vista: econômico, social e pessoal. Nesse caso, as principais vítimas são o Estado, através da Previdência Social, que arca com os direitos do trabalhador durante o afastamento e o próprio trabalhador, que além de ter reduzido seu salário, fica "fora" do mercado de trabalho, e dependendo do tipo de acidente pode haver um comprometimento de seu amor próprio, achar-se incompetente, etc., e incapaz do sustento de seu lar (Ribeiro, 2000).

Nota-se, que existe alta notificação dos acidentes com afastamento inferior a 15 dias, por parte das empresas, que preferem assumir a responsabilidade do pagamento do afastamento nesse período a correr o risco de se responsabilizar por um afastamento superior a esse tempo, isen-

\section{TABELA 4}

Distribuição dos Acidentes do Trabalho em Áreas Rurais, segundo Principais Tipos de Acidente Estado de São Paulo-1997/1999

\begin{tabular}{lrr}
\hline Tipos de Acidentes do Trabalho & \multicolumn{1}{c}{ Total } & $\%$ \\
\hline Acidentes-Tipo & 51.644 & 100,00 \\
Acidentes com objetos cortantes/contundentes & 22.869 & 44,28 \\
Demais tipos de acidente & 9.901 & 19,17 \\
Traumatismos ou lesões causados por & & \\
instrumento de trabalho & 6.033 & 11,68 \\
Acidentes causados por plantas & 6.007 & 11,63 \\
Queda/torção/escorregar/emárea rural & 4.232 & 8,19 \\
Acidentes com objetos inanimados & 2.495 & 4,83 \\
lgnorado & 107 & 0,21 \\
& & \\
Doenças do Trabalho & 5.354 & 100,00 \\
Traumatismos ou lesões decorrentes de movimentos & 2.747 & 51,31 \\
Lesões por esforços repetitivos/mal súbito/estresse & 2.524 & 47,14 \\
Demais tipos de acidente & 65 & 1,21 \\
lgnorado & 18 & 0,34 \\
\hline
\end{tabular}

Fonte: Fundação Seade; Fundacentro/MTE. 


\section{GRÁFICO 1}

Distribuição dos Acidentes do Trabalho em Áreas Rurais, segundo Período de Afastamento

Estado de São Paulo-1997/1999

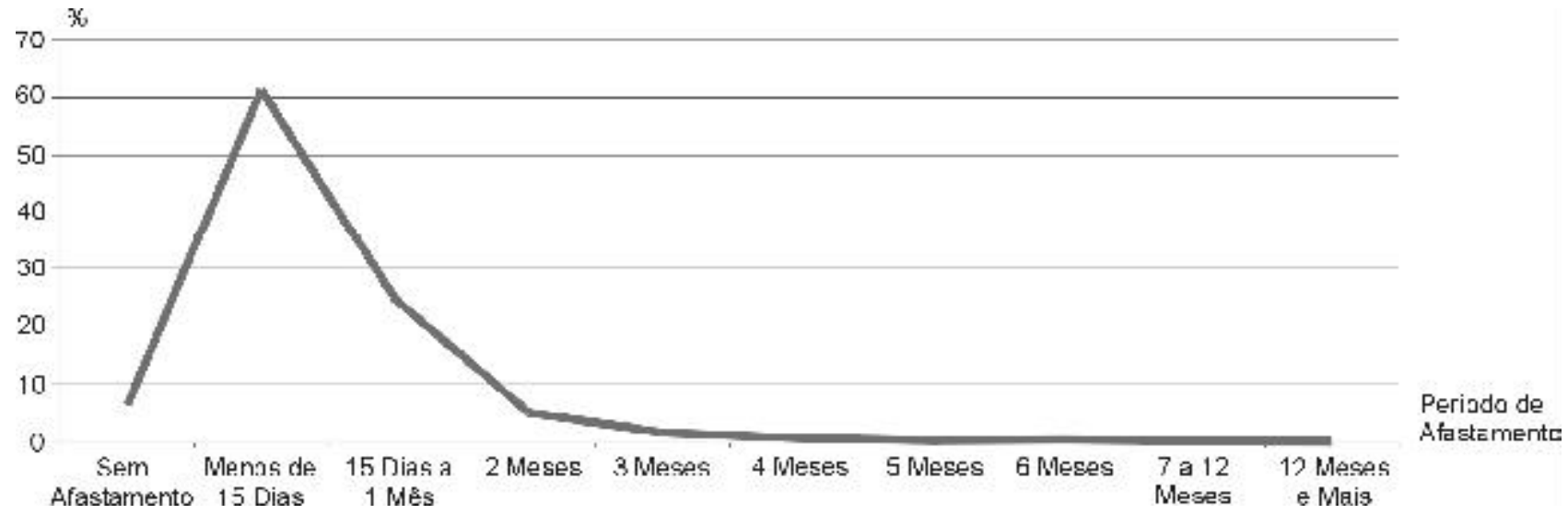

Fonte: Fundação Seade; Fundacentro/MTE.

tando-se assim do custo de um tratamento mais demorado que recai sobre a Previdência Social.

As partes do corpo atingidas nos acidentes-tipo e das doenças do trabalho são muitas e diversificadas. Vale ressaltar que o mesmo acidente ou doença do trabalho pode atingir mais de uma parte do corpo do trabalhador.

Para as doenças do trabalho as partes do corpo que mais sofreram lesões foram os membros superiores, em que os braços com $52,3 \%$ e as mãos com $42,3 \%$ foram maioria, a seguir apresentou-se o tronco com $39,6 \%$.

Para os acidentes-tipo, as partes do corpo mais atingidas foram os membros superiores $39,0 \%$ e os inferiores $38,8 \%$, ambos encontram-se muito sujeitos aos traumatismos causados pelas ferramentas de trabalho, como o facão. Nos membros superiores, as partes mais atingidas são os dedos $46,3 \%$ e as mãos, enquanto nos inferiores tanto as pernas como os pés têm pesos muito parecidos, $50 \%$ e $49,7 \%$, respectivamente.

Observa-se uma supremacia do sexo masculino, com quase $90 \%$ dos casos de acidente do trabalho, coerente com a composição de gênero da população dos trabalhadores das áreas rurais, que em sua maioria $(77,1 \%)$ são homens e 22,9\%, mulheres, segundo o Censo Agropecuário de 1995-1996. Por tipo de acidentes são as doenças ocupacionais onde o sexo feminino tem maior percentual de participação com $18,9 \%$ dos casos.

Com relação a idade os trabalhadores que apresentaram maior proporção de acidente do trabalho foram aqueles com idades entre 20 e 24 anos.
TABELA 5

Distribuição dos Acidentes do Trabalho em Áreas Rurais, segundo Grandes Partes do Corpo Atingidas Estado de São Paulo-1997/1999

\begin{tabular}{|c|c|c|c|c|}
\hline \multirow{2}{*}{ Partes do Corpo Atingidas } & \multicolumn{2}{|c|}{ Acidentes-Tipo } & \multicolumn{2}{|c|}{ Doença do Trabalho } \\
\hline & Casos & $\%$ & Casos & $\%$ \\
\hline TOTAL & 51.644 & & 5.354 & \\
\hline Membros Inferiores & 20.025 & 38,78 & 238 & 4,45 \\
\hline Pernas & 10.007 & 49,97 & 167 & 70,17 \\
\hline Pés & 9.945 & 49,66 & 56 & 23,53 \\
\hline Membros Superiores & 20.162 & 39,04 & 2.851 & 53,25 \\
\hline Dedos & 9.327 & 46,26 & 106 & 3,72 \\
\hline Mãos & 7.726 & 38,32 & 1.206 & 42,30 \\
\hline Braços & 3.016 & 14,96 & 1.490 & 52,26 \\
\hline Tronco & 2.975 & 5,76 & 2.123 & 39,65 \\
\hline Cabeça & 8.478 & 16,42 & 101 & 1,89 \\
\hline Olhos & 6.832 & 82,11 & 8 & 18,18 \\
\hline Ouvidos & 101 & 1,21 & 14 & 31,82 \\
\hline
\end{tabular}

Fonte: Fundação Seade; Fundacentro/MTE.

Nota: Como o mesmo acidente pode traumatizar mais de uma parte do corpo, a soma das parcelas não corresponde ao total dos itens levantados.

Os acidentes-tipo ocorrem em todos os grupos etários, e são mais freqüentes proporcionalmente nas idades mais tenras, de 15 a 24 anos. Com o avançar da idade, mesmo sendo alto, passa a apresentar uma tendência de queda. Asdoenças do trabalho, por sua vez, só ultrapassam os acidentes-tipo nas faixas etárias de 25 a 39 anos, idades mais avançadas quando comparadas as dos acidentes-tipo, porém ainda prematuras, mas que já indicam alguns anos de trabalho duro, realizados com gestos mecânicos e repetitivos. Para os aci- 


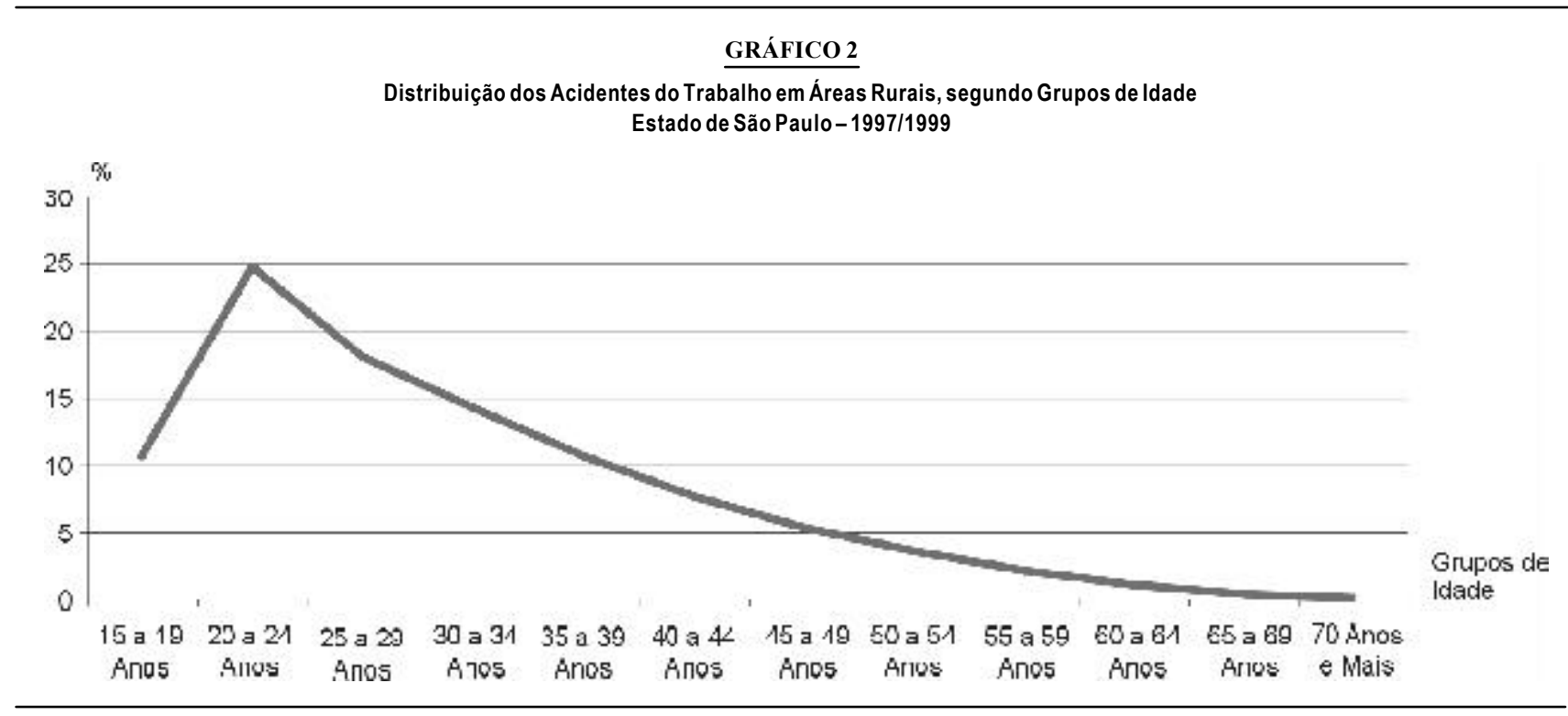

Fonte: Fundação Seade; Fundacentro/MTE.

dentes de trajeto, o pico acontece entre os 20 e 24 anos, apresentando depois dos 30 e 34 anos a tendência de queda já observada para doenças do trabalho e os acidentes-tipo. Chama atenção que esse tipo de acidente com o avançar da idade, entre os 40-44 e 60-65 anos, mostra-se mais significativo em relação aos demais.

Distinto das classificações citadas, os acidentes de trajeto não são exclusivos e nem estão diretamente relacionados a essas classes trabalhistas, como são a maioria dos acidentes-tipo. Embora registre uma proporção menor de eventos, é um acidente no qual todos os trabalhadores apresentam-se vulneráveis, basta realizar o exercício de ir e vir da residência ao local de trabalho e vice-versa, como cumprir o horário destinado ao almoço.

Com relação a esses acidentes, a maioria ocorreu no percurso entre residência/trabalho. Considerando os meios de locomoção utilizados pelo trabalhador rural em seu movimento físico diário, que apresentaram as maiores proporções de acidente do trabalho, encontram-se: o ônibus, com praticamente $44 \%$ de todos os acidentes, a pé, com $25 \%$ dos acidentes e numa menor proporção, a bicicleta com $7,3 \%$, entre outros. Nota-se que entre os meios de locomoção mais representativos, com exceção de um (a pé), os demais envolviam algum tipo de veículo.

\section{CONSIDERAÇÕES FINAIS}

O mais inédito deste trabalho de parceria entre a Fundação Seade e a Fundacentro foi a extensão territorial desse
TABELA 6

Distribuição dos Acidentes de Trajeto, segundo Meio de Locomoção Estado de São Paulo-1997/1999

\begin{tabular}{lrr}
\hline Meios de Locomoção & Total & $\%$ \\
\hline Total & 929 & 100,00 \\
Ônibus & 408 & 43,92 \\
Apé(parado, carregando, empilhando) & 232 & 24,97 \\
Bicicleta (duas rodas) & 68 & 7,32 \\
Caminhão & 47 & 5,06 \\
Motocicleta & 42 & 4,52 \\
Kombi, Besta, Van, Sprinter & 15 & 1,61 \\
Carreta & 13 & 1,40 \\
Automóvel & 11 & 1,18 \\
Ônibus coletivo intermunicipal & 9 & 0,97 \\
Animais Quadrúpedes (cavalo, pônei, jumento, burro, jegue) & 6 & 0,65 \\
Caminhonete ou Picape & 4 & 0,43 \\
Mobilete & 4 & 0,43 \\
Nãopreenchido & 70 & 7,53 \\
\hline
\end{tabular}

Fonte: Fundação Seade; Fundacentro/MTE.

levantamento, que abrangeu todo o Estado de São Paulo, resultando em um rico banco de dados, contendo detalhes valiosos sobre o trabalhador acidentado, proporcionando um estudo minucioso e uma análise dos diferenciais regionais.

Resultado satisfatório também foi tomar conhecimento da grande notificação dos acidentes rurais, talvez isso possa servir para olhar como mais atenção essa classe trabalhista tão sofrida e merecedora de respeito, e assim, contribuir de alguma forma para a prevenção dos acidentes do trabalho e das doenças profissionais na área rural. 
Mesmo sendo uma potência do setor primário, com alta tecnologia, o Estado de São Paulo apresenta elevada participação de trabalhadores rurais que exercem atividades manuais vinculadas, principalmente, ao plantio e ao corte da cana-de-açúcar. Esses trabalhadores foram, de acordo com a pesquisa, um dos mais suscetíveis a apresentar acidentes do trabalho.

Foi constatado uma média diária de 53,2 acidentes do trabalho, nos quais a maioria ocorreu no exercício da profissão, ou seja, os acidentes classificados de tipo. Esses trabalhadores, em sua grande parte, se acidentaram com suas próprias ferramentas diárias de trabalho, registrando cortes ou traumatismos; as partes do corpo mais atingidas são os membros superiores e inferiores, afastando aproximadamente $86 \%$ desses trabalhadores de suas atividades laborais, no máximo até 1 mês.

A doença do trabalho, que também afetou e afastou trabalhadores teve como principais agentes causadores a torção e o mal jeito, que ocasionaram traumatismos ou lesões decorrentes de movimentos, afetando principalmente os membros superiores.

É interessante observar que apesar dos acidentes do trabalho espalharem-se por todo o interior paulista, diversos municípios que registraram os maiores volumes de acidentes do trabalho encontram-se geograficamente localizados nas áreas de maior valor comercial do Estado e as que empregam mais mão-de-obra para a atividade agrícola, onde concentram-se as atividades dos complexos agroindustriais de cana-de-açúcar e da laranja, que são as mesorregiões de Ribeirão Preto, Araraquara, Campinas e Piracicaba.

\section{NOTAS}

1. Considerou-se agroindústria apenas as atividades vinculadas ao primeiro processamento de matérias-primas derivadas da agropecuária (Fundação Seade, 1999).

2. Lavoura Permanente: compreendeu a área plantada ou em preparo para o plantio de culturas de longa duração, que após a colheita não necessitassem de novo plantio, e que produzissem por vários anos sucessivos. Foram incluídas nesta categoria as áreas ocupadas por viveiros de mudas de culturas permanentes. Lavoura Temporária : abrangeu as áreas plantadas ou em preparo para o plantio de culturas de curta duração (em geral, menor que um ano), e que necessitassem quase sempre de novo plantio após cada colheita. Incluíram-se, também nessa categoria as áreas das plantas forrageiras destinadas ao corte.

3. Ver, a respeito: <www.saudeetrabalho.com.br>.

4. Ver, a respeito: 〈www.unica.com.br/pages/agroindustria_alta.asp>.

5. Com a proibição da queimada da cana crua, a mecanização da colheita deve atingir grande parte da área cultivada em solos com declividade compatível com esta prática nos próximos anos, provocando mudanças importantes para as regiões de cultivo e para os trabalhadores, resultando na diminuição do volume de empregos.

\section{REFERÊNCIAS BIBLIOGRÁFICAS}

ALESSI, N.P.; NAVARRO, L. Saúde e trabalho rural: o caso dos trabalhadores da cultura canavieira na Região de Ribeirão Preto, São Paulo, Brasil. Caderno de Saúde Pública, Rio de Janeiro, 13 (supl. 2), p.111-121, 1997.

BALSADI, O.V.; BORIN, M.R.; JULIO, J.E. A agropecuária paulista . São Paulo: Fundação Seade, 2001. Mimeografado [Texto elaborado a partir do Caderno Agricultura do Fórum São Paulo Século XXI que a Fundação Seade produziu para a Assembléia Legislativa do Estado].

BELIK, W.; BOLLIGER, F.P.; SILVA, J.G. Agroindústria paulista: heterogeneidade e reestruturação. São Paulo em Perspectiva, São Paulo, Fundação Seade, v.13, n.1-2, p.93-102, jan./jun. 1999.

FUNDAÇÃO IBGE. Censo Agropecuário de 1995/96.

FUNDAÇÃO SEADE. São Paulo em Perspectiva, v.13, n.1-2, jan./ jun. 1999.

FUNDAÇÃO SEADE/ FUNDACENTRO. Estudos e pesquisas sobre saúde e segurança no transporte coletivo urbano, rural e de cargas perigosas, maio 2001 [Relatório final do projeto].

LOPES, R.M. Acidentes do trabalho na agricultura, Botucatu - SP. Revista Brasileira de Saúde Ocupacional, v.10, n.39, p.12-17, jul./ set. 1982.

OLIVEIRA, L.O.; TARTAGLIA, J.C. A dinâmica municipal de agricultura paulista. São Paulo em Perspectiva, São Paulo, Fundação Seade, v.7, n.3, p.60-71, jul./set. 1993.

PREVIDÊNCIA SOCIAL. Anuário Estatístico da Previdência Social. Brasília: v.7, 1999.

REVISTA ECOLOGIA E DESENVOLVIMENTO, ano 10, n.81, p.4243,2000 .

RIBEIRO, M.C.S. de A. Acidentes de trabalho referidos por trabalhadores moradores na Região Metropolitana de São Paulo em 1994: um levantamento de base populacional. Dissertação (Mestrado) - Faculdade de Medicina da Universidade de São Paulo, São Paulo, 2000.

SILVA, J.G. et al. O rural paulista: muito além do agrícola e do agrário. São Paulo em Perspectiva, São Paulo, Fundação Seade, v.10, n.2, p.60-72, abr./jun. 1996.

SILVA, J.G., BALSADI, O.V.; GROSSI, M.E. del. O emprego rural e a mercatilização do espaço agrário. São Paulo em Perspectiva, São Paulo, Fundação Seade, v.11, n.2, p.50-64, abr./jun. 1997.

SÃO PAULO. Cana Web/Jornal Cana. Disponível em: <http://www.ilab.com.br/clientes.htm\#Barra>. Acesso em: 2002.

WALDVOGEL, B.C. Acidentes do trabalho: vida ativa interrompida Novos desafios em saúde e segurança no trabalho. Belo Horizonte: PUC-Minas, Instituto de Relações do Trabalho e Fundacentro, 2001.

. Acidentes do trabalho - os casos fatais: a questão da identificação e da mensuração. 1999. Tese (Doutorado) - Faculdade de Saúde Pública da Universidade de São Paulo, São Paulo, 1999. [Publicada pela Fundacentro: Coleção de Fontes e Análise, v.1, n.1, mar. 2002].

Monica La Porte Teixeira: Matemática, Analista da Fundação Seade (mlaporte@seade.gov.br).

Rosa Maria Vieira de Freitas: Socióloga, Analista da Fundação Seade (rfreitas@seade.gov.br). 